\title{
CARACTERIZAÇÃO DA BACIA DO CÓRREGO DAS PALMEIRAS EM RIBEIRÃO PRETO - SP
}

\author{
Matheus Felipe Oliveira ${ }^{1}$ \\ Ernesto Vendramini Bergamaschi ${ }^{2}$
}

RESUMO: As bacias hidrográficas são importantes unidades de planejamento e gerenciamento, permitindo a caracterização, reconhecimento e avaliação dos recursos hídricos. A utilização desta unidade proporciona uma visão sistêmica e integrada, devido sua delimitação e à interdependência dos fatores climatológicos, hidrológicos, geológicos e ecológicos. O presente trabalho visa apresentar os aspectos físicos e sociais da bacia do córrego das Palmeiras, em Ribeirão Preto - SP. Sua escolha se deve ao fato desta unidade estar situada em área de afloramento e recarga do aquífero Guarani, possuindo assim, maior vulnerabilidade natural à poluição. O presente estudo tem como finalidade a caracterização da área em questão, fornecendo subsídios para o estabelecimento de prioridades na tomada de decisões, contribuindo assim, com a manutenção das águas subsuperficiais, através de uma gestão que preserve a renovação do sistema.

\section{INTRODUÇÃO}

O município de Ribeirão Preto tem uma população de 604.682 habitantes (IBGE, 2010). Localizado a nordeste do estado de São Paulo, é considerada centro de referência no setor da agroindústria sucro-alcooleira, fazendo com que a cidade se enquadre no grupo 1 do Índice Paulista de

\footnotetext{
1 Licenciado em Geografia pela UNESP - Campus de Ourinhos. mtf matheus@hotmail.com ${ }^{2}$ Bacharelado Geografafia pela UNESP - Campus de Ourinhos. evbernesto@hotmail.com
} 
Responsabilidade Social (IPRS), caracterizado por elevados índices de riqueza e bons níveis nos indicadores sociais.

$\mathrm{Na}$ década de 70, o surgimento do Programa Nacional do Álcool (PROALCOOL), contribuiu com forte incentivo público, impulsionando assim, o desenvolvimento do município que já produzia cana-de-açúcar desde os anos 30. Segundo DEDECCA, et al $(2009$, p. 33)

[...] os principais impactos do aumento da produção canavieira na região foram: substituição de outras culturas pela cana-de-açúcar (monocultura); valorização das terras e maior concentração fundiária; substituição da mão-de-obra permanente pela temporária, com residência na cidade e o aumento dos fluxos migratórios, com destaque para o movimento sazonal na época da safra.

Segundo a Secretaria de Planejamento e Desenvolvimento Regional (Governo do Estado de São Paulo, 2012) em 2010 o município registrou um grau de urbanização superior a 99,7\%. A taxa de crescimento populacional, no período de 2000-2010, foi de 1,82\% ao ano, número acima da média estadual.

O município está inserido em grande parte nas áreas de recarga do aquífero Guarani, afloramento dos arenitos Botucatu e Pirambóia. Os fatores econômicos aliados ao alto índice de crescimento demográfico e expansão urbana geram dois graves problemas: demanda crescente por água e um consumo que supera em muito a média nacional; e a ocupação das áreas de recarga impedindo a renovação do sistema. A estes problemas acrescenta-se as perdas no sistema de abastecimento, que chegam a quase $50 \%$ do total extraído.

Considerando que o abastecimento publico é realizado exclusivamente por água subterrânea, estima-se que a explotação de água é quase duas vezes maior que sua capacidade de renovação no sistema. O bombeamento intensivo dos poços para suprir a demanda e o alto consumo, ocasionou o rebaixamento dos níveis hídricos, ocasionando cones de rebaixamento, dificultando a explotação da água, e exigindo a perfuração de poços cada vez mais profundos. 
A escolha pela adoção da bacia hidrográfica como unidade territorial no presente trabalho, se dá pelo enfoque de preservação de um recurso hídrico atendendo as necessidades de uma visão ecossistêmica, devido as características da água, que é um bem renovável que circula continuamente da atmosfera ao subsolo. Além disso, a bacia hidrográfica permite pelo estudo de suas variáveis, interpretar através da parte, a soma do todo. Esta unidade foi a adotada pela lei 9.433 de 1997 para instituição da Política Nacional de Recursos Hídricos e para a atuação do Sistema Nacional de Gerenciamento de Recursos Hídricos.

A visão ecossistêmica da bacia hidrográfica pode ser resumida pelas palavras de SANTOS $(2004$, p. 85$)$

Toda ocorrência de eventos em uma bacia hidrográfica, de origem antrópica ou natural, interfere na dinâmica deste sistema, na quantidade dos cursos de água e sua qualidade. A medida de algumas de suas variáveis permite interpretar, pelo menos parcialmente a soma dos eventos. Essa é uma das peculiaridades que induz os planejadores a escolherem a bacia hidrográfica como uma unidade de gestão.

\section{CARACTERIZAÇÃO DA ÁREA DE ESTUDO}

A bacia do Córrego das Palmeiras (Figura 1) possui $37 \mathrm{~km}^{2}$ e está inserida na zona leste do município e em trechos da zona norte e é composta pelos Jardim Juliana, Parque dos Servidores, Jardim Helena, Jardim Ouro Branco, Conjunto Habitacional Palmeiras, complexo Ribeirão Verde, Jardim Aeroporto, Jardim Salgado Filho e Vila Hípica. A bacia do Córrego das Palmeiras faz parte da bacia hidrográfica do rio Pardo, UGRHI-04. O córrego das Palmeiras é afluente da margem esquerda do rio Pardo, com $10.120 \mathrm{~m}$ de comprimento. (LAURENTIIS, 2010, p. 33) 

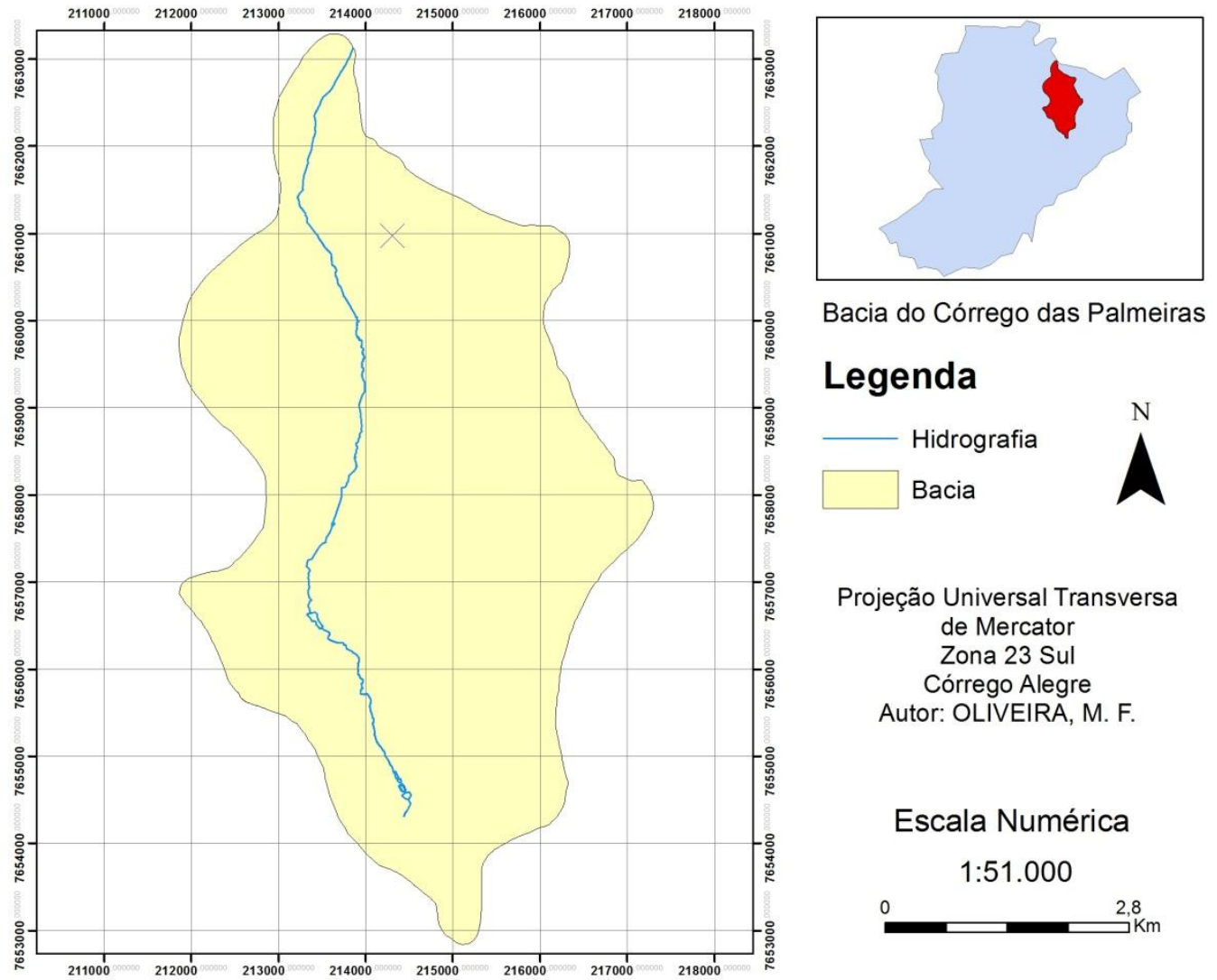

Bacia do Córrego das Palmeiras

\section{Legenda}

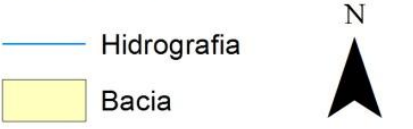

Projeção Universal Transversa de Mercator

Zona 23 Sul Córrego Alegre Autor: OLIVEIRA, M. F.

Escala Numérica

$1: 51.000$

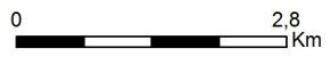

Figura 1. Delimitação da bacia do Córrego das Palmeiras.

A zona leste do município é uma das maiores áreas de expansão urbana, sendo influenciada por uma forte especulação imobiliária, apresentando grandes vazios urbanos, que acabam por valorizar as áreas de seu entorno que vão sendo paulatinamente ocupadas. Devido ao solo de qualidade inferior para agricultura, suas terras possuem um baixo valor, diferentemente dos solos argilosos da formação Serra Geral a oeste, o que faz com que seja um atrativo para moradores classe baixa, influenciados pelos especuladores que se amparam na fraca atuação do poder público para a conservação desta área de grande vulnerabilidade natural.

Os diferentes usos e ocupação nesta área, onde convivem áreas urbanas e rurais, representam graves problemas que podem provocar a contaminação das águas subsuperficiais. 
Há na nascente do córrego das Palmeiras (Figura 2), a presença áreas urbanizadas, constituindo uma densidade demográfica grande em uma área de recarga do aquífero. Há também nesse ponto a presença de fossas, representando uma parte da poluição de suas águas, que tem como principal poluente, esgoto doméstico.

O descaso do poder público com a área também pode ser presenciado, como é o caso do antigo "Lixão" Jardim Juliana (Figura 2), que ignorou além do Código Ambiental Municipal - que prevê a não instalação em zonas de recarga, aterros sanitários ou industriais necessitando de licenciamentos para a deposição de resíduos sólidos - a legislação sobre a deposição de resíduos sólidos e os riscos a população instalada nos conjuntos habitacionais denominados Jardim Juliana "A", Jardim Palmeiras I e II e Parque dos Servidores.

Outras fontes que representam risco para águas subterrâneas como o cemitério Bom Pastor (Figura 2). No cemitério, os caixões são enterrados diretamente na terra, em grande parte sem jazigos, ampliando a potencialidade de contaminação das águas por necrochorume. 

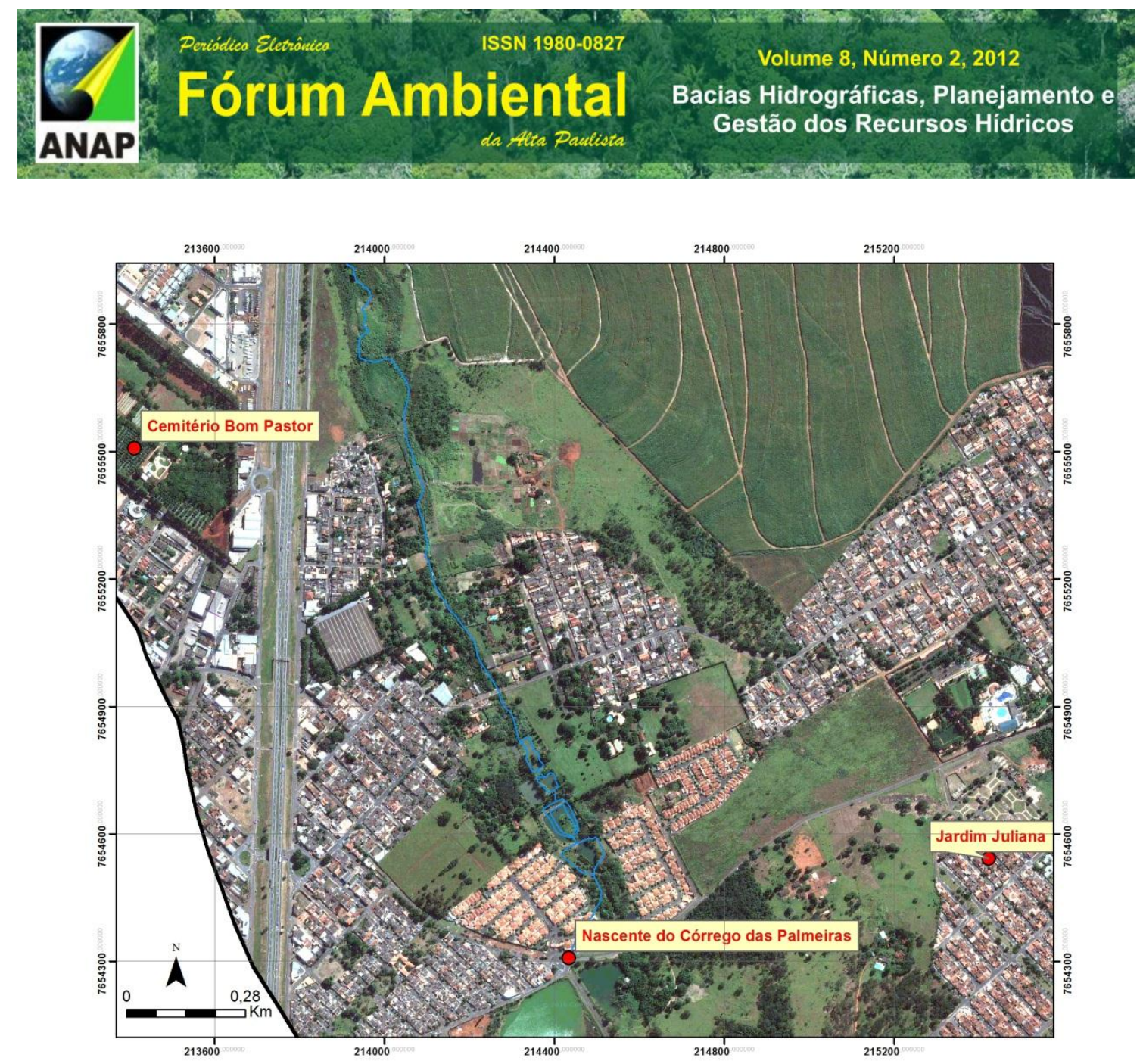

Figura 2. Localização dos pontos a montante do Córrego das Palmeiras (Fonte: Google Earth - adaptado).

Algumas fontes pontuais de cargas poluidoras se encontram na bacia, como fossas sépticas e negras, em locais sem infraestrutura de saneamento básico. É o caso de algumas favelas localizadas no Jardim Aeroporto (Figura 3), que enfrentam um processo de desocupação para atender as determinações do EIA/RIMA, criando um conflito entre a urbanização e a vegetação natural remanescente do local.

Segundo Villar (2009, p. 72), a Política Urbana Municipal prevê no art.

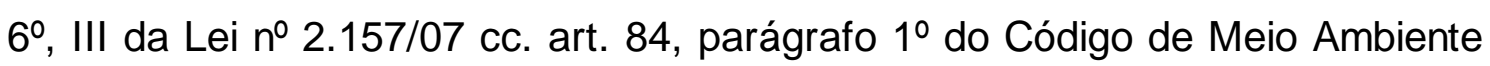
que as áreas de recarga representam locais de grande vulnerabilidade e fragilidade, sendo classificadas como Zonas de Uso Especial, garantindo assim a recarga do aquífero. O art.62, III da Lei oㅜ 2.157/07 e o art. 43, permite lotes com área mínima de $140 \mathrm{~m}^{2}$ e densidade máxima permitida de $850 \mathrm{hab} / \mathrm{ha}$ 


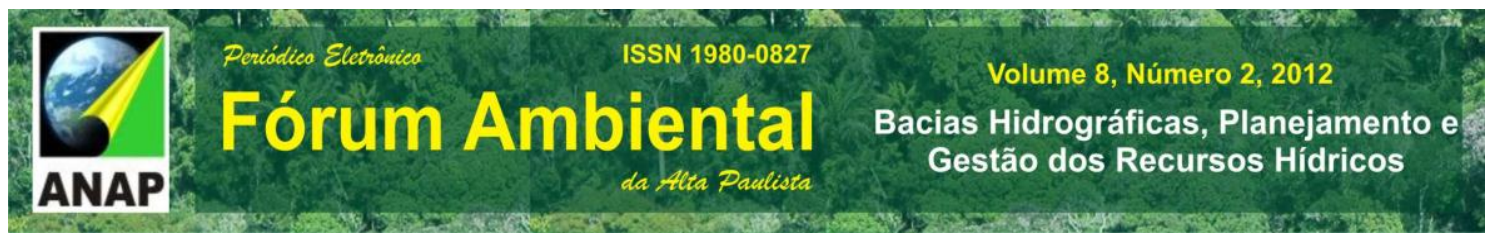

respectivamente, representando uma falha legislativa na contenção do índice de impermeabilização do solo, na qual a contenção deve ser de $10 \%$ por lote, comprometendo a recarga do aquífero.

No Complexo Ribeirão Verde (Figura 3), os lotes reduzidos, chegam muitas vezes a ter $100 \%$ de edificação, não permitindo a percolação para recarga do Aquífero Guarani como sugerido no EIA-RIMA do empreendimento determinado pela prefeitura. ENDO (2005, p. 29)

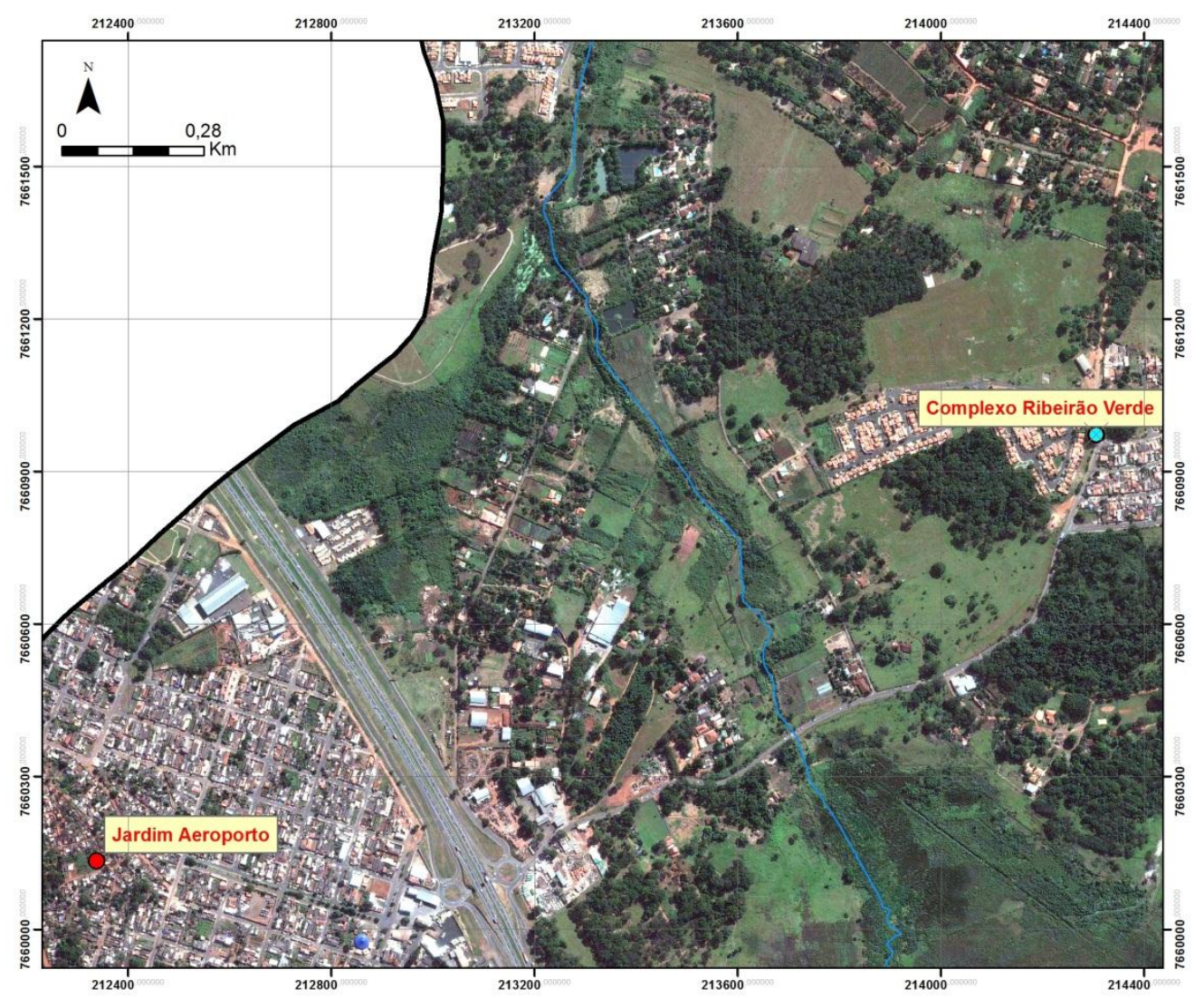

Figura 3. Localização dos pontos a jusante do Córrego das Palmeiras (Fonte: Google Earth - adaptado).

A ocupação destas áreas e sua consequente impermeabilização geram riscos não só para a qualidade das águas subterrâneas e para os níveis hídricos, mas também podem agravar alguns problemas já existentes, como as enchentes na cidade. 


\section{MATERIAIS E MÉTODOS}

O software utilizado na pesquisa foi o ArcGis 9.3. Para a delimitação da bacia do Córrego das Palmeiras, foram utilizadas cartas topográficas dos municípios de Ribeirão Preto e Serrana, na escala de 1:50.000, adquiridas na biblioteca digital do IBGE (biblioteca.ibge.gov.br), formando um mosaico na qual foram vetorizadas as curvas de nível e o curso hídrico. O sistema de coordenadas utilizado no trabalho foi o mesmo das cartas topográficas, projeção Universal Transversa de Mercator, Córrego Alegre zona 23 Sul.

Para uma maior precisão nas curvas de nível, foram extraídas as curvas de nível da imagem SRTM (Shuttle Radar Topography Mission), adquirida na página do Instituto Nacional de Pesquisas Espaciais (INPE).

Para a elaboração do mapa de identificação dos pontos citados no trabalho, foi utilizado uma imagem do Google Earth, que foi georreferenciada baseada nas cartas topográficas do município de Ribeirão Preto na escala de 1:2000, adquiridas no site da Secretaria de Planejamento e Gestão Pública (www.ribeiraopreto.sp.gov.br/splan/escala/i28mapas.php).

\section{CONCLUSÃO}

Adotar a bacia como unidade territorial de planejamento e gestão é uma forma de contribuição para mitigar ou mesmo sanar a grande quantidade de problemas na qual enfrenta o município de Ribeirão Preto no que se refere a preservação de seus recursos hídricos.

Embora o zoneamento do município de Ribeirão Preto classifique essa área como zona de uso especial, poucas melhorias são feitas para tentar reverter o quadro atual. Alguns dos pontos destacados no trabalho demonstram a situação de descaso do poder público em relação a área onde está inserida a bacia, onde $\mathrm{o}$ interesse dos agentes capitalistas ultrapassa a capacidade de controle local. 
O município que se encontra em um processo de desenvolvimento econômico constante, apresentando níveis de urbanização e crescimento demográfico cada vez maior, necessita que sejam adotadas com urgência práticas para redução dos impactos previstos.

\section{REFERÊNCIAS}

BRASIL. IBGE. Instituto Brasileiro de Geografia e Estatística. <www.ibge.gov.br/catálogos/indicadores>. Acesso em: 18 jun. 2011.

DEDECCA, C. MONTALI, L. BAENINGER, R. Estudos Regionais: Pólo Econômico de Ribeirão Preto. 2009. Disponível em: < http://www.nepo.unicamp.br/simesp/Site/Estudos/RP.pdf> Acesso em: 30 ago. 2012.

ENDO, R. M. A formação da paisagem urbana do Complexo Ribeirão Verde: uma proposta comunitária de educação ambiental. 2005. $391 \mathrm{f}$. Dissertação (Mestre em Educação - Núcleo Temático de Educação Ambiental) - Instituto de Biociências, da Universidade Estadual Paulista, Campus de Rio Claro, Rio Claro, 2005. Disponível em: < http://www.athena.biblioteca.unesp.br/exlibris/bd/brc/33004137064P2/2005/end o_rm_me_rcla.pdf>Acesso em: 27 jun. 2012.

GOVERNO DO ESTADO DE SÃO PAULO. Caracterização socioeconômica das regiões do Estado de São Paulo: Região Administrativa de Ribeirão Preto.

Disponível em:

http://www.planejamento.sp.gov.br/noti_anexo/files/uam/trabalhos/Ribeir\%C3\% A3o\%20Preto.pdf> Acesso em: 22 mai. 2012.

LAURENTIIS, Laura Barzaghi de. Moradores em ação: constituição da paisagem no bairro Ribeirão Verde, em Ribeirão Preto - SP. 2010. 
Dissertação (Mestrado em Paisagem e Ambiente) - Faculdade de Arquitetura e Urbanismo, Universidade de São Paulo, São Paulo, 2010. Disponível em: <http://www.teses.usp.br/teses/disponiveis/16/16135/tde-16072010-133422/>. Acesso em: 08 mai. 2012.

SANTOS, R. F. dos. Planejamento Ambiental: teoria e prática. São Paulo. Oficina de Textos, 2004.

VILLAR, P. C.; NEPOMUCENO, O. Áreas de recarga de Ribeirão Preto e os riscos urbanos, In: II Congresso Aqüífero Guarani/Workshops. Memória... Ribeirão Preto: IG - Institulo Geológico de São Paulo. LEBAC/UNESP, 2008 pg. 70-74., 2., 2008, Ribeirão Preto-SP.

VILLAR, Pilar Carolina. Gestão das Áreas de Recarga do Aqüífero Guarani: o caso do município de Ribeirão Preto, São Paulo. 2008. Dissertação (Mestrado em Ciência Ambiental) - Ciência Ambiental, Universidade de São Paulo, São Paulo, 2008. Disponível em: <http://www.teses.usp.br/teses/disponiveis/90/90131/tde-26052010-100627/>. Acesso em: 30 ago. 2011. 